\title{
Robotic Partial Nephrectomy in a Jehovah's Witness Population
}

\author{
Harbin AC, Kaplan JR, Labrada L, Lee Z, Bromberg M, Reese A and Eun DD* \\ Department of Urology, Temple University Hospital, Temple University School of Medicine, Philadelphia, USA
}

Received: August 04, 2015; Accepted: August 15, 2015; Published: September 01, 2015

*Corresponding author: Daniel D. Eun, Department of Urology, Temple University Hospital, Temple University School of Medicine, Philadelphia, USA, PA 19140, Tel: 215-707-3375; E-mail: Daniel.eun@tuhs.temple.edu

\begin{abstract}
Background: Recent interest in "bloodless" surgery places the urologic surgeon in a difficult position, especially as surgeries such as partial nephrectomy with an increased risk of bleeding, grow in popularity and the availability of blood for transfusion decreases. Jehovah's Witnesses are a religious group that refuses blood transfusion on religious grounds, which necessitates surgery in a setting where blood transfusion is not an option.

Objective: To present our experience and technique with Jehovah's Witness patients undergoing robot-assisted partial nephrectomy.

Design: Prospectively maintained IRB approved database of a single surgeon's patient cohort of Jehovah's Witness patients.

Results: Eight Jehovah's Witness patients underwent robotassisted laparoscopic partial nephrectomy during the study period. One patient was given erythropoietin postoperatively for anemia. There were no intra-operative complications.

Conclusions: Jehovah's Witness status should not preclude consideration of partial nephrectomy in patients with renal masses concerning for cancer.
\end{abstract}

\section{Introduction}

Recently, the surgical literature has seen a rise in the popularity of bloodless surgery [1,2]. Concerns over the added morbidity associated with Blood Transfusion (BT) $[3,4]$ and the chronic undersupply of available blood [5] are the driving factors behind the recent revolution in surgical care. Many of these data have come out of the thoracic and cardiac surgery sphere, where patients are especially susceptible to the cardiovascular and pulmonary complications of BT [6].

Many techniques have already been applied to curb the use of BT in the perioperative setting. Such innovations include the use of genetically engineered drugs to stimulate marrow production of blood components [7], laparoscopic/robotic and transcatheter techniques [1], technology that recycles a patient's own blood [8], and drugs that reduce blood loss during surgery (aprotinin, antifibrinolytics)[9].
Another group in which BT utilization is limited is the Jehovah's Witness (JW) population. The JW religion is a Christianbased faith founded in the United States characterized by the avoidance of BT, even if it may lead to morbidity or mortality [10]. Because of this belief, many JW patients may experience difficulty in finding surgeons willing to perform elective major operations.

Partial Nephrectomy (PN) has been recognized as the standard of care operation for the small renal mass $(<4 \mathrm{~cm})[11]$. While PN has been heralded as a nephron-sparing surgical approach, the incidence of post-operative complications - including hemorrhage and pseudoaneurysm - may prevent widespread adoption [12]. One potential advantage of Robotic Partial Nephrectomy (RPN) is that it may mitigate the hemorrhagic complications and thus make this operation more accessible [13]. This could have particular applications in the JW population.

We present the first published series of RPN in a group of JW patients.

\section{Methods}

After proper internal review board approval, we prospectively maintained a database of JW patients undergoing RPN between 2010-2014. The procedures were performed by a single surgeon at two institutions. Preoperative optimization with a hematologist was sought on every procedure, as a part of the Bloodless Medicine program at our institution.

All procedures were performed in a transperitoneal fashion. Intraoperative ultrasound was used to localize the tumor, and artery-only clamping was performed unless venous backbleeding was encountered. Tumor excision was performed using a standard technique, with cold scissors and gentle retraction.

Renorrhaphy was performed using our innovation of the sliding-clip technique [14], which is unique to our institution. The suture consists of two V-LOC (Medtronic, Minneapolis, MN) sutures attached at the tails Figure 1. The first layer of closure is performed using the 3-0 V-LOC with a CV-23 needle, which is similar to a RV-1. Critical to this step is the approximation of the corticomedullary junction, as this tends to be the stronger layer. Also important in this step is the closure of any collecting 
system violations, or obvious open vessels. Early unclamping of the renal hilum is performed after this layer, so that any open vessels are still visible. Next, the cortex and capsule are closed in a single layer using the $0 \mathrm{~V}$-LOC with a GS-21 needle. This layer utilizes the sliding-clip technique in order to re-approximate the cortex. Prior to placement of the final suture, hemostatic agent is installed into the defect.

Patients were followed closely in the postoperative period for signs of anemia. Erythropoietin and supplemental iron therapy were utilized as indicated. Statistical analysis was performed on perioperative and follow- up data.

\section{Results}

Overall eight RPN were performed on JW patients between September 2010 and September 2014. Demographic and perioperative data can be found in Table 1. Mean age was 58.5 (52-78) years old and mean body mass index was 37.8 (27.8-61). Mean mass size was $3.2 \mathrm{~cm}$ (1.6-7.7) and mean nephrometry score 7.3 (5-11).

There were no intra operative complications. One patient required a brief postoperative stay in the intensive care unit for anemia, where erythropoietin was administered (Clavien II). One patient also received erythropoietin preoperatively. Six of the tumors were clear cell Renal Cell Carcinoma (RCC), one was papillary RCC and one was a benign cyst. None of the cases were converted to total nephrectomy and there were no open conversions. There were no tumor recurrences. Intraoperative cell salvage (Cell saver - [Haemonetics, Braintree, MA]) was not utilized in any of our cases to preserve oncologic effectiveness. Two patients experienced an incisional hernia in the late postoperative period, and neither required surgery. Median follow-up was 21 months.

\section{Discussion}

This is the first description of RPN in a JW population. In

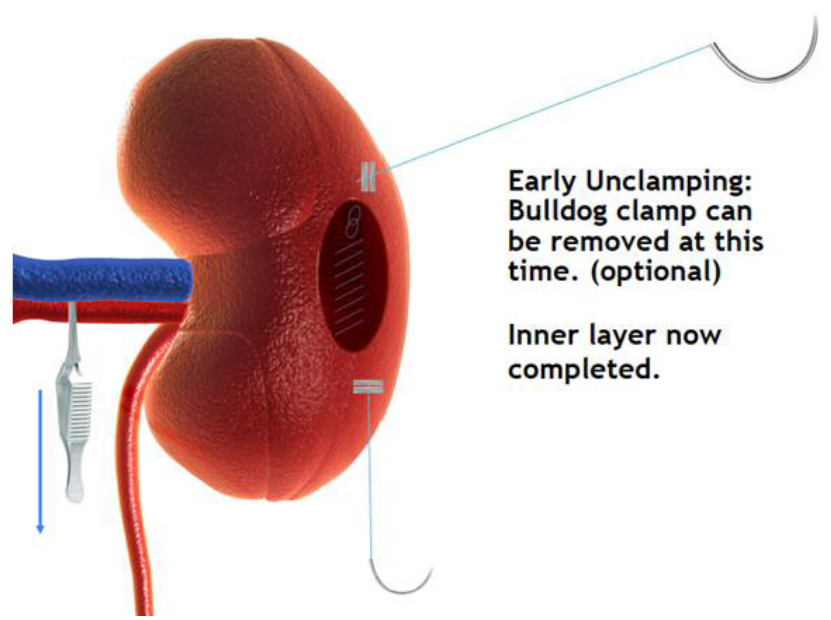

Figure 1: Diagram illustrating the standard renorrhaphy at our institution. The initial layer of 3-0 V-LOC approximating the corticomedullary layer is complete. The arterial clamp will be removed prior to completing the cortex/capsule layer.
Table 1: Demographic and perioperative data of JW patients undergoing RPN between 2010-2014.

\begin{tabular}{|c|c|c|}
\hline RPN between 2010-2014. & Mean & Range \\
\hline Age & 58.5 & $52-78$ \\
\hline Body Mass Index & 37.8 & $27.8-61$ \\
\hline ASA Score & 2.4 & $1-3$ \\
\hline Mass Size (cm) & 2.8 & $1.8-6.0$ \\
\hline $\begin{array}{c}\text { RENAL Nephrometry } \\
\text { Score }\end{array}$ & 6.3 & $5-9$ \\
\hline $\begin{array}{c}\text { Change in eGFR (dl/ } \\
\text { min) }\end{array}$ & 4.7 & $8-22$ \\
\hline $\begin{array}{c}\text { Change in Hemoglobin } \\
\text { (gm/dl) }\end{array}$ & 2.3 & $0.6-4.3$ \\
\hline $\begin{array}{c}\text { Console Time (min) } \\
\text { Estimated Blood Loss } \\
\text { (mL) }\end{array}$ & 165 & $65-149$ \\
\hline $\begin{array}{c}\text { Warm Ischemia Time } \\
\text { (min) }\end{array}$ & 2.6 & $11-45$ \\
\hline Length of Stay (days) & 9.6 & $1-7$ \\
\hline
\end{tabular}

our experience, RPN represents a safe and feasible option for JW patients with renal masses, and may allow better access to care in a potentially underserved population.

The Jehovah's Witness religion is a restorationist Christian denomination with several beliefs which differ from mainstream Christianity [15]. The most pertinent of these differences is their beliefs on BT. Based on their interpretation of the Bible, JW patients are forbidden from accepting transfusion containing any cells or plasma, even if it is necessary to sustain life [16].

The JW religion has been a major current in the recent trend of bloodless medicine and surgery. The broad avoidance of BT is also supported by concerns of specific complications, including Transfusion Associated Lung Injury (TRALI) [3], infectious disease transmission [17], allergic reactions [18], and volume overload [19]. These issues, coupled with the persistent shortage of available blood, have led many to advocate a restricted or even bloodless approach to medicine and surgery.

Multiple authors have investigated the potential benefits of transfusion restriction in both medical and surgical patients. Herbert et al reported the results of a multi-center prospective trial comparing a restrictive vs. liberal BT protocol in critical care patients. They found that restrictions on BT were associated with a lower overall mortality as well as lower 30-day mortality in younger, healthier patients $(8.7 \%$ in restricted vs. $16.1 \%, p=$ 0.03 ) [3]. Similar results were reported by a retrospective study of critical care patients in a large academic institution in the United States. The authors of that study found that increased BT was independently associated with longer hospital stay (RR 3.2 in patients undergoing $>4 \mathrm{BT}$ ) and increased mortality (RR 4.1 if $>4$ BT) [20]. Roubinian et al found that after implementation of blood conservation strategies in critical care patients, the incidence of BT decreased significantly but mortality did not change [21].

Similarly, the conservative BT approach has been applied to 
surgical patients. Hajjar etal performed a prospective randomized trial comparing conservative vs. liberal BT indications after cardiac surgery, and found 30-day mortality to be non-inferior in the conservative group [22]. A similar trend was found in hip replacement patients at 60-day follow up, in whom liberal and conservative BT strategies carried the same rate of mortality and ambulation timeframe [23]. Kilic recently conducted a comprehensive literature review of the available studies on BT after cardiac surgery. The authors concluded that there is a fine line between the morbidity caused by anemia and that caused by BT, and a more evidence-based approach is needed [24].

Urologic surgery has yet to experience a large-scale revolution in bloodless surgery, likely related to the lack of surgeries requiring high rates of BT. PN, now the standard of care for renal masses less than $4 \mathrm{~cm}$ [11], represents an operation with high potential for BT. Hemorrhage is a significant concern both during and immediately after the operation. While the reported rate of this complication is variable (0.8\%-8.4\%), it can be catastrophic and result in high rate of BT $[11,12,25,26]$. In addition to early hemorrhage, late bleeding can occur in the form of a pseudoaneurysm. This complication, which is unique to PN, has been attributed to fistula formation by needle repositioning during renorrhaphy [27]. Therefore, PN is widely held as a risky operation for patients who must avoid BT, and prevention of bleeding is paramount for a successful a PN in the JW population.

Intraoperative red blood cell salvage was not utilized in our series. This technology, commonly utilized in the form of Cellsaver, has been an important aspect of the implementation of bloodless surgery programs [1]. Salvage techniques allow the collection, washing, concentration and reinfusion of shed blood [8]. While they have been effective in reducing autologous transfusion requirements, variable perceptions about their acceptance in the JW community has led to the limited application [28].Our rationale for not using this technology was based on the potential concerns of spreading tumor cells to the patient's vasculature [29], as well as the ability of our renorrhaphy technique to minimize bleeding.

In our study, we were able to safely perform eight PN without the need for BT. Two innovations which may explain our success are the inherent hemostatic advantages of therobotic approach and the unique renorrhaphy technique we used. The pneumoperitoneum of Laparoscopic Partial Nephrectomy (LPN) and RPN may have a mitigating effect on intraoperative hemorrhage, as has been proposed in the prostatectomy literature [30]. In addition, the 3-dimensional vision and wristed instruments of RPN may enhance the reconstructive portions compared to LPN [31]. One study retrospectively reviewed RPN and LPN at three institutions, and found that both blood loss (155 vs. $196 \mathrm{ml}, \mathrm{p}=0.03$ ) and Warm Ischemia Time (WIT) (19.7 vs. 28.4 minutes, $p<0.0001$ ) were lower in the RPN group [32].

In addition to the use of robotic technology, an effective renorrhaphy can be helpful in preventing bleeding after PN. Our approach is simple, yet effective. Our two-layer closure starts with a 3-0 running V-LOC (Medtronic, Minneapolis, MN) suture approximating the cortico-medullary junction and collecting system while the hilum is still clamped. The second layer consists of a 12 inch running horizontal mattress $0 \mathrm{~V}$-LOC suture which tightly reapproximates the renal capsule and cortex, and is performed after the early removal of the renal hilar clamp (Figure 2). We believe this technique greatly enhances the ability to close the defect tightly, thereby decreasing the risk of postoperative hemorrhage or fistulization.

These techniques represent a few simple and reproducible ways to prevent excessive blood loss during PN. Pneumoperitoneum and robotic technology have previously been shown to limit blood loss, and thus boost BT prevention strategies [1,33]. While we do believe our renorrhaphy technique represents an important innovation in bloodless surgery, it should be viewed more as an augmentation of existing techniques rather than a completely novel method. Though there have never been any side-by-side comparisons of renorrhaphy techniques, we believe our transfusion rate of zero and our mean EBL of $165 \mathrm{~mL}$ ( $\mathrm{sd}=150$ ) is comparable to that of the two largest RPN series by Long et al [33] $(\mathrm{BT}=12.1 \%$; $\mathrm{EBL}=280.2, \mathrm{sd}=$ 313.6) and Masson-Lecomte et al [34] (BT $=6 \%$; EBL $=244.8$, sd =365.4).

Although none of the patients in our study received BT, two patients did require erythropoietin infusion. Recombinant Human Erythropoietin (RHE) is one of many supportive measures - including Cell saver, coagulating instruments, volume expanders and controlled hypotension - that can support bloodless surgery in high risk procedures [1]. RHE bolsters bone marrow production of erythrocytes, and can be given in the pre- or postoperative setting $[35,36]$. There are no prospective, randomized trials to determine appropriate dosing, but case reports have recorded success with ranges as wide as 60-500 Units/kg given subcutaneously either daily or several times per week. Supplemental medications such as Iron, B12 and folic

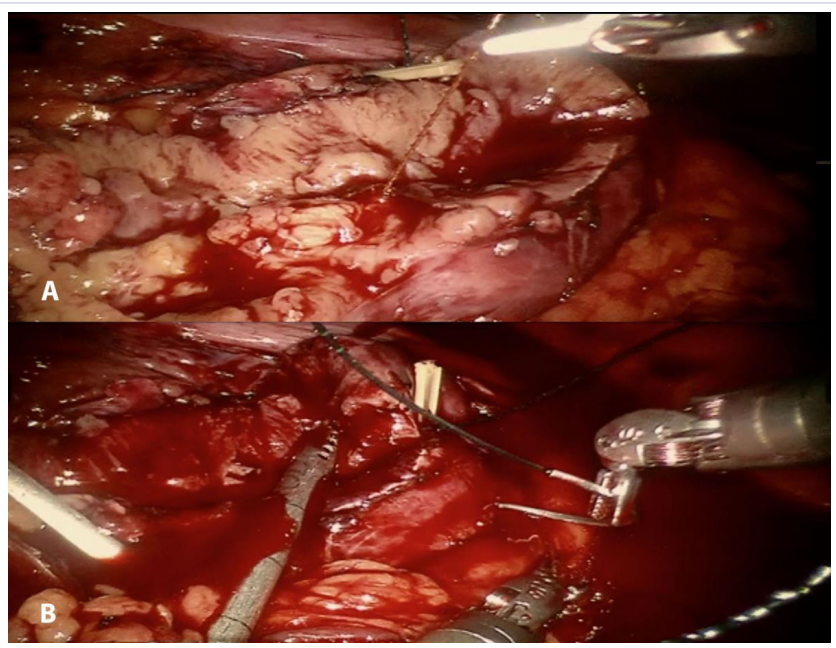

Figure 2: Intraoperative photographs of standard renorrhaphy at our institution.

(A) Inner layer 2-0 V-Loc in a standard baseball-stitch fashion and (B) Outer layer $0 \mathrm{~V}$-Loc in a horizontal mattress fashion. 
acid can be given simultaneously [35]. Although there are no controlled prospective trials of RHE in JW populations, multiple case reports in the surgical [37] and burn [38] literature report successful usage and a perceived survival benefit with its use. It should be noted, however, that multiple prospective studies in critical care patients have failed to show a benefit comparable to that of BT [39]. We recommend RHE only to be given under the direct supervision of a hematologist.

A final important factor in our experience was the team approach utilized in our institution. All patients were well known to the multi-disciplinary bloodless medicine program, which included health professionals in all aspects of care. Most importantly, the hematology team was consulted both preoperatively and during the hospital stay in all cases. We believe this team-based approach is important in safely guiding JW patients through the operation and recovery.

Our study is limited by a small size and retrospective design. While we have a large JW population at our institution, the religion is generally not common enough to generate a large cohort. For that reason our study does represent the largest report of this kind.

\section{Conclusion}

In conclusion, we report the largest report of PN in a JW population. We experienced clinical success in all patients, and only reported one postoperative complication (Clavien II). We believe our favorable experience is due to the use of robotic technology as well as our particular renorrhaphy technique. The JW religion represents a challenging population when it comes to an elective surgery with a high risk for bleeding complications; however we believe every effort should be made to ensure these patients have safe and equitable access to care. Whenever possible, referral to a high volume center should be considered, where a team approach can be taken.

\section{References}

1. Shander A. Surgery without blood. Critical care medicine. 2003 Dec; 31(12 Suppl): S708-14.

2. Society of Thoracic Surgeons Blood Conservation Guideline Task F, Ferraris VA, Ferraris SP, Saha SP, Hessel EA, 2nd, Haan CK, et al. Perioperative blood transfusion and blood conservation in cardiac surgery: the Society of Thoracic Surgeons and The Society of Cardiovascular Anesthesiologists clinical practice guideline. The Annals of thoracic surgery. 2007; 83 (5 Suppl): S27-86.

3. Hebert PC, Wells G, Blajchman MA, Marshall J, Martin C, Pagliarello G, et al. A multicenter, randomized, controlled clinical trial of transfusion requirements in critical care. Transfusion Requirements in Critical Care Investigators, Canadian Critical Care Trials Group. The New England journal of medicine. 1999 11;340(6): 409-17.

4. Reeves BC, Murphy GJ. Increased mortality, morbidity, and cost associated with red blood cell transfusion after cardiac surgery. Current opinion in cardiology.2008; 23(6):607-12. doi: 10.1097/ HCO.0b013e328310fc95.

5. Greinacher A, Fendrich K, Alpen U, Hoffmann W. Impact of demographic changes on the blood supply: Mecklenburg-West Pomerania as a model region for Europe. Transfusion. 2007; 47(3): 395-401.
6. Crescenzi G, Torracca L, Capestro F, Matteucci ML, Rossi M. Allogenic blood transfusion in cardiac surgery. Journal of cardiac surgery. 2012; 27(5): 594-9. doi: 10.1111/j.1540-8191.2012.01522.x.

7. Atabek U, Alvarez R, Pello MJ, Alexander JB, Camishion RC, Curry C, et al. Erythropoetin accelerates hematocrit recovery in post-surgical anemia. The American surgeon. 1995; 61(1): 74-7.

8. Popovsky MA. Transfusion medicine. The New England journal of medicine. 1999; 341(2): 125-6; author reply 126-7.

9. Murkin JM, Shannon NA, Bourne RB, Rorabeck $\mathrm{CH}$, Cruickshank M, Wyile G. Aprotinin decreases blood loss in patients undergoing revision or bilateral total hip arthroplasty. Anesthesia and analgesia. 1995; 80(2): 343-8.

10. Sniecinski R, Levy JH. What is blood and what is not? Caring for the Jehovah's Witness patient undergoing cardiac surgery. Anesthesia and analgesia. 2007; 104(4): 753-4.

11. Campbell SC, Novick AC, Belldegrun A, Blute ML, Chow GK, Derweesh $\mathrm{IH}$, et al. Guideline for management of the clinical T1 renal mass. The Journal of Urology. 2009; 182(4): 1271-9. doi: 10.1016/j. juro.2009.07.004.

12. Stephenson AJ, Hakimi AA, Snyder ME, Russo P. Complications of radical and partial nephrectomy in a large contemporary cohort. The Journal of Urology. 2004; 171(1): 130-4.

13. Benway BM, Bhayani SB. Surgical outcomes of robot-assisted partial nephrectomy. BJU international. 2011; $108(6$ Pt 2): 955-61. doi: 10.1111/j.1464-410X.2011.

14. Benway BM, Wang AJ, Cabello JM, Bhayani SB. Robotic partial nephrectomy with sliding-clip renorrhaphy: technique and outcomes. European Urology. 2009; 55(3): 592-9.doi: 10.1016/j. eururo.2009.06.038

15. Bowman RM. Jehovah's Witnesses. Grand Rapids, Mich.: Zondervan; 1995. 85 p.p.

16. Watchtower Bible and Tract Society of New York., International Bible Students Association., Watch Tower Bible and Tract Society of Pennsylvania. United in worship of the only true God. 1st. ed. Brooklyn, N.Y., U.S.A.: Watchtower Bible and Tract Society of New York : International Bible Students Association; 1983. 191 p. p.

17. Fournier-Wirth C, Jaffrezic-Renault N, Coste J. Detection of blood-transmissible agents: can screening be miniaturized? Transfusion. 2010; 50(9): 2032-45. doi: 10.1111/j.15372995.2010.02678.x.

18. Hirayama F. Current understanding of allergic transfusion reactions: incidence, pathogenesis, laboratory tests, prevention and treatment. British journal of hematology. 2013; 160(4): 434-44. doi: 10.1111/ bjh.12150.

19. Alam A, Lin Y, Lima A, Hansen M, Callum JL. The prevention of transfusion-associated circulatory overload. Transfusion medicine reviews. 2013; 27(2): 105-12. doi: 10.1016/j.tmrv.2013.02.001.

20. Corwin HL, Gettinger A, Pearl RG, Fink MP, Levy MM, Abraham E, et al. The CRIT Study: Anemia and blood transfusion in the critically ill-current clinical practice in the United States. Critical care medicine. 2004; 32(1): 39-52.

21. Escobar LE, Restif O, Yung V, Favi M, Pons DJ, Medina-Vogel G. Spatial and temporal trends of bat-borne rabies in Chile. Epidemiology and infection. 2015 May;143(7):1486-94. doi: 10.1017/ S095026881400226X.

22. Hajjar LA, Vincent JL, Galas FR, Nakamura RE, Silva CM, Santos MH, 
et al. Transfusion requirements after cardiac surgery: the TRACS randomized controlled trial. JAMA: the Journal of the American Medical Association. 2010; 304(14): 1559-67. doi: 10.1001/jama.2010.1446.

23. Carson JL, Terrin ML, Noveck H, Sanders DW, Chaitman BR, Rhoads $\mathrm{GG}$, et al. Liberal or restrictive transfusion in high-risk patients after hip surgery. The New England journal of medicine. 2011; 365(26): 2453-62. doi: 10.1056/NEJMoa1012452.

24. Kilic A, Whitman GJ. Blood transfusions in cardiac surgery: indications, risks, and conservation strategies. TheAnnals of thoracic surgery. 2014; 97(2): 726-34. doi: 10.1016/j.athoracsur.2013.08.016.

25. Montag S, Rais-Bahrami S, Seideman CA, Rastinehad AR, Vira MA Kavoussi LR, et al. Delayed haemorrhage after laparoscopic partial nephrectomy: frequency and angiographic findings. BJU international. 2011; 107 (9): 1460-6. doi: 10.1111/j.1464-410X.2010.09645.X

26. Jung S, Min GE, Chung BI, Jeon SH. Risk factors for postoperative hemorrhage after partial nephrectomy. Korean Journal of Urology. 2014; 55(1): 17-22. doi: 10.4111/kju.2014.55.1.17

27. Singh D, Gill IS. Renal artery pseudoaneurysm following laparoscopic partial nephrectomy. The Journal of Urology. 2005; 174(6): 2256-9.

28. Waters JH, Potter PS. Cell salvage in the Jehovah's Witness patient. Anesthesia and analgesia. 2000; 90(1): 229-30.

29. Klimberg I, Sirois R, Wajsman Z, Baker J. Intraoperative autotransfusion in urologic oncology. Archives of Surgery. 1986; 121(11): 1326-9.

30. Smith JA, Jr., Herrell SD. Robotic-assisted laparoscopic prostatectomy: do minimally invasive approaches offer significant advantages? Journal of Clinical Oncology: official journal of the American Society of Clinical Oncology. 2005; 23(32): 8170-5.

31. Rogers CG, Metwalli A, Blatt AM, Bratslavsky G, Menon M, Linehan WM, et al. Robotic partial nephrectomy for renal hilar tumors: a multiinstitutional analysis. The Journal of Urology. 2008; 180(6): 2353-6; discussion 6. doi: 10.1016/j.juro.2008.08.022.
32. Benway BM, Bhayani SB, Rogers CG, Dulabon LM, Patel MN, Lipkin $M$, et al. Robot assisted partial nephrectomy versus laparoscopic partial nephrectomy for renal tumors: a multi-institutional analysis of perioperative outcomes. The Journal of urology. 2009; 182(3): 86672. doi: 10.1016/j.juro.2009.05.037.

33. Long JA, Yakoubi R, Lee B, Guillotreau J, Autorino R, Laydner H, et al. Robotic versus laparoscopic partial nephrectomy for complex tumors: comparison of perioperative outcomes. European urology. 2012; 61(6): 1257-62. doi: 10.1016/j.eururo.2012.03.012

34. Masson-Lecomte A, Bensalah K, Seringe E, Vaessen C, de la Taille A, Doumerc N, et al. A prospective comparison of surgical and pathological outcomes obtained after robot-assisted or pure laparoscopic partial nephrectomy in moderate to complex renal tumours: results from a French multicentre collaborative study. BJU international. 2013; 111(2): 256-63. doi: 10.1111/j.1464-410X.2012.11528.x.

35. Ball AM, Winstead PS. Recombinant human erythropoietin therapy in critically ill Jehovah's Witnesses. Pharmacotherapy. 2008; 28(11): 1383-90. doi: 10.1592/phco.28.11.1383.

36. Marsh JC, Bevan DH. Haematological care of the Jehovah's Witness patient. British journal of haematology. 2002; 119(1): 25-37.

37. Wolff M, Fandrey J, Hirner A, Jelkmann W. Perioperative use of recombinant human erythropoietin in patients refusing blood transfusions. Pathophysiological considerations based on 5 cases. European journal of haematology. 1997; 58(3): 154-9.

38. Boshkov LK, Tredget EE, Janowska-Wieczorek A. Recombinant human erythropoietin for a Jehovah's Witness with anemia of thermal injury. American journal of hematology. 1991; 37(1): 53-4.

39. Jelkmann I, Jelkmann W. Impact of erythropoietin on intensive care unit patients. Transfusion medicine and hemotherapy: offizielles Organ der Deutschen Gesellschaft fur Transfusionsmedizin und Immunhamatologie. 2013; 40(5): 310-8. doi: 10.1159/000354128. 